\title{
Histone H3 K36 methylation is mediated by a trans-histone methylation pathway involving an interaction between Set 2 and histone $\mathrm{H} 4$
}

\author{
Hai-Ning Du, Ian M. Fingerman, and Scott D. Briggs ${ }^{1}$ \\ Department of Biochemistry and Purdue Cancer Center, Purdue University, West Lafayette, Indiana 47907, USA
}

\begin{abstract}
Set2-mediated $\mathrm{H} 3 \mathrm{~K} 36$ methylation is an important histone modification on chromatin during transcription elongation. Although Set2 associates with the phosphorylated C-terminal domain (CTD) of RNA polymerase II (RNAPII), the mechanism of Set2 binding to chromatin and subsequent exertion of its methyltransferase activity is relatively uncharacterized. We identified a critical lysine residue in histone $\mathrm{H} 4$ that is needed for interaction with Set2 and proper H3 K36 di- and trimethylation. We also determined that the $\mathrm{N}$ terminus of Set 2 contains a histone $\mathrm{H} 4$ interaction motif that allows Set2 to bind histone $\mathrm{H} 4$ and nucleosomes. A Set2 mutant lacking the histone $\mathrm{H} 4$ interaction motif is able to bind to the phosphorylated CTD of RNAPII and associate with gene-specific loci but is defective for $\mathrm{H} 3 \mathrm{~K} 36 \mathrm{di}$ - and trimethylation. In addition, this Set2 mutant shows increased $\mathrm{H} 4$ acetylation and resistance to 6-Azauracil. Overall, our study defines a new interaction between Set2 and histone $\mathrm{H} 4$ that mediates trans-histone regulation of H3 K36 methylation, which is needed for the preventative maintenance and integrity of the genome.
\end{abstract}

[Keywords: Set2; histone; methylation; transcriptional elongation; chromatin; trans-histone]

Supplemental material is available at http://www.genesdev.org.

Received May 28, 2008; revised version accepted August 19, 2008.

Post-translational modifications such as acetylation, methylation, phosphorylation, and ubiquitination occur on histones (Vaquero et al. 2003; Kouzarides 2007). These histone modifications can directly alter chromatin structure and function and/or recruit effector proteins to chromatin (Martin and Zhang 2005; Taverna et al. 2007). Although histone modifications can be directly regulated by enzymes that add or remove their corresponding modifications, histone modifications can also be regulated by other modifications either in cis, on the same histone, or in trans, on different histones (Fischle et al. 2003; Latham and Dent 2007). This crosstalk between different modifications on one or more histones is thought to provide a specific pattern of information for proper regulation of gene expression (Fischle et al. 2003; Shogren-Knaak and Peterson 2006; Latham and Dent 2007).

One of the initial trans-histone pathways identified was discovered in Saccharomyces cerevisiae. In this trans-histone pathway, H2B monoubiquitination is required for Set1-mediated H3 K4 di- and trimethylation

${ }^{1}$ Corresponding author.

E-MAIL sdbriggs@purdue.edu; FAX (765) 494-7897.

Article is online at http://www.genesdev.org/cgi/doi/10.1101/gad.1700008. and Dot1-mediated H3 K79 di- and trimethylation but not for Set2-mediated H3 K36 methylation (Briggs et al. 2002; Dover et al. 2002; Ng et al. 2002; Sun and Allis 2002; Shahbazian et al. 2005). Recently, a modification independent trans-histone pathway was identified, in which a charge-based interaction between the basic patch of residues located in the $\mathrm{N}$ terminus of histone $\mathrm{H} 4$ and small acidic region at the $\mathrm{C}$ terminus of Dot 1 is needed for H3 K79 di- and trimethylation (Fingerman et al. 2007). This interaction between Dot 1 and histone H4 is also needed to establish and maintain proper heterochromatin and euchromatin domains (Altaf et al. 2007; Fingerman et al. 2007).

Until now, a trans-histone pathway that specifically regulates Set2-mediated H3 K36 methylation has not been identified. However, studies have shown that $\mathrm{H} 3$ K36 methylation can mediate a cis- and trans-histone deacetylation of histone $\mathrm{H} 3$ and H4 (Carrozza et al. 2005; Joshi and Struhl 2005; Keogh et al. 2005; Li et al. 2007a). The cis- and trans-histone deacetylation mediated by $\mathrm{H} 3$ K36 methylation occurs when the chromodomain (CHD) of Eaf3 and the plant homeobox domain (PHD) of Rco1, which are two subunits of the Rpd3S histone deacetylase complex, specifically recognize the H3 K36 methylated histones (Carrozza et al. 2005; Joshi and Struhl 2005; Keogh et al. 2005; Li et al. 2007a). This recognition sub- 
sequently allows the Rpd3S complex to deacetylate histones $\mathrm{H} 3$ and $\mathrm{H} 4$ within the ORF and prevent spurious intragenic transcription (Carrozza et al. 2005; Joshi and Struhl 2005; Keogh et al. 2005; Li et al. 2007a,b).

Initial biochemical studies with Set 2 would suggest that H3 K36 methylation is functioning to facilitate transcription elongation. This is supported by studies showing that Set2 associates with the phosphorylated C-terminal domain (CTD) of the elongating RNA polymerase II (RNAPII) and that histone $\mathrm{H} 3 \mathrm{~K} 36$ di- and trimethylation is enriched at the $3^{\prime}$ ends of ORFs (Li et al. 2002, 2003; Xiao et al. 2003; Pokholok et al. 2005; Rao et al. 2005). However, histone H3 K36 trimethylation but not dimethylation has a positive correlation with increasing transcriptional activity (Pokholok et al. 2005; Rao et al. 2005). In contrast, other studies have indicated that Set2 might be acting to inhibit or oppose transcriptional elongation. For example, Set 2 can repress transcription of a lac $Z$ reporter construct, and deletion of Set2 can increase basal transcription of GAL4 (Strahl et al. 2002; Landry et al. 2003). Furthermore, yeast strains carrying mutants or deletions of known factors that promote transcriptional elongation, such as the Burl kinase or the Spt16 subunit of FACT, showed sensitivity to 6-Azauracil (6-AU) while a set2 $2 \Delta$ strain had increased resistance to 6-AU (Murray et al. 2001; Keogh et al. 2003; Kizer et al. 2005; Biswas et al. 2006). In addition, deletion of Set2 in bur1s or spt16 temperature sensitive strains can suppress growth defects when grown at permissive and nonpermissive temperatures, respectively (Keogh et al. 2003; Biswas et al. 2006; Chu et al. 2006). Recently, H3 K36 methylation has been shown to recruit the Rpd3S histone deacetylase complex to restore a repressed chromatin state behind the elongating RNAPII, thereby preventing aberrant intragenic transcription (Carrozza et al. 2005; Joshi and Struhl 2005; Keogh et al. 2005). Taken together, we suggest Set2-mediated H3 K36 methylation is needed for "preventative maintenance" during transcriptional elongation. Therefore, identifying new cis- and trans-histone pathways that play preventive maintenance roles in chromatin will be vital in our understanding of chromatin structure and function.

In this study, we identified a new trans-histone pathway that provides mechanistic insights into how Set2 engages chromatin and catalyzes H3 K36 methylation. We identified a conserved lysine in the L1 loop of histone $\mathrm{H} 4$ that is needed to interact with Set2 and for histone H3 K36 di- and trimethylation. We also determined that the $\mathrm{N}$ terminus of Set 2 contains a histone $\mathrm{H} 4$ interaction motif that is needed for histone $\mathrm{H} 4$ and nucleosomes binding. Interestingly, a Set2 mutant lacking the histone H4 interaction motif can associate with the phosphorylated CTD of RNAPII and be recruited to gene-specific loci but is defective in histone $\mathrm{H} 3 \mathrm{~K} 36$ di- and trimethylation. In addition, this Set 2 mutant shows increased $\mathrm{H} 4$ acetylation and resistance to 6-AU when compared with wild-type cells. Together, our data suggest that Set2, after being recruited by the phosphorylated CTD of RNAPII, must engage the nucleosome by binding to histone $\mathrm{H} 4$ to allow for proper $\mathrm{H} 3 \mathrm{~K} 36$ methylation and transcriptional elongation. Therefore, this trans-histone pathway plays a crucial step in the preventative maintenance and integrity of the genome.

\section{Results}

Histone H4 facilitates histone H3 methylation by Set2 in vitro

Although previous reports have shown that recombinant Set2 prefers to methylate nucleosomes rather than free core histones, our results and other reports demonstrate that recombinant Set2 can methylate recombinant histone H3 (rH3) (Strahl et al. 2002; Li et al. 2007a). To further investigate the substrate specificity of Set2, in vitro histone methyltransferase (HMT) assays were performed using recombinant $\mathrm{N}$-terminal CBP-tagged Set2 (CBP-Set2) incubated with different histone substrates. Total ${ }^{3} \mathrm{H}$-methyl incorporation was measured by filter binding and liquid scintillation counting or by gel and fluorography. Consistent with previous reports, Set2 demonstrates robust HMT activity on nucleosomal substrates that is specific to histone $\mathrm{H} 3$ (Fig. 1A,B, lane 2), whereas Set2 shows relatively weak HMT activity on rH3 (Fig. 1A,B, lane 4). Intriguingly, when Set2 is incu-
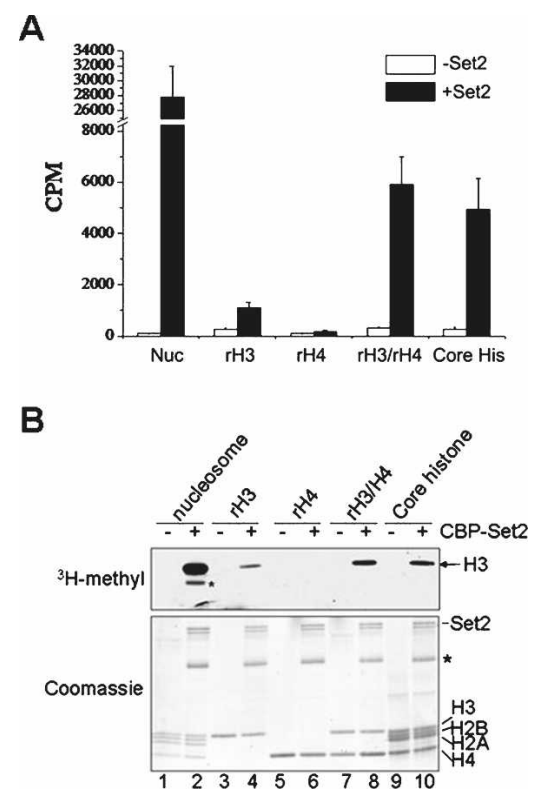

Figure 1. Histone $\mathrm{H} 4$ facilitates histone $\mathrm{H} 3$ methylation by Set2 in vitro. (A) HMT assays were performed using purified chicken mononucleosomes (Nuc), recombinant histone $\mathrm{H} 3$ (rH3), recombinant histone $\mathrm{H} 4$ (rH4), a mixture of $\mathrm{rH} 3$ and $\mathrm{rH} 4$, or core histones (Core His) isolated from human 293T cells incubated with or without recombinant, purified CBP-Set 2 protein. HMT reactions were analyzed by filter-binding assays and scintillation counting to measure total ${ }^{3} \mathrm{H}$-methyl incorporation. $(B)$ The same reaction samples in $A$ were resolved by SDSPAGE and analyzed by fluorography $\left({ }^{3} \mathrm{H}\right.$-methyl) and Coomassie blue staining. Asterisks represent breakdown products of histone $\mathrm{H} 3$ or CBP-Set2. 
bated with $\mathrm{rH} 3$ in the presence of recombinant histone $\mathrm{H} 4(\mathrm{rH} 4)$, there is a five- to sevenfold increase in activity on $\mathrm{rH} 3$ (Fig. 1A,B, lane 8 vs. lane 4). This enhancement of HMT activity does not come from methylation of histone $\mathrm{H} 4$, as no detectable Set2 activity was observed when it was incubated with $\mathrm{rH} 4$ alone (Fig. 1A,B, lane 6). In contrast, Set 2 incubated with $\mathrm{rH} 3$ in the presence of $\mathrm{rH} 2 \mathrm{~A}$ or $\mathrm{rH} 2 \mathrm{~B}$ shows no detectable increase in HMT activity on $\mathrm{rH} 3$ (data not shown). Nucleosomal DNA may also contribute to Set2 activity toward H3, as HMT activity on nucleosomes is greater than on core histones (Fig. 1A,B, lane 2 vs. lane 10). Collectively, these data indicate that Set2 utilizes histone $\mathrm{H} 4$ to facilitate histone $\mathrm{H} 3$ methylation. Recently, Dot1 was shown to have a similar requirement for histone $\mathrm{H} 4$. However, histone H4 mutations that prevented H3 K79 methylation do not disrupt H3 K36 methylation (Fingerman et al. 2007). Therefore, we wanted to further explore Set2's requirement for histone $\mathrm{H} 4$ and to determine if we identified a new trans-histone pathway.

\section{Interactions between Histone $\mathrm{H} 4$ and Set2 are needed for histone H3 K36 di- and trimethylation}

Given that histone $\mathrm{H} 4$ facilitates Set2-mediated histone H3 methylation in vitro, we wanted to examine if histone $\mathrm{H} 4$ participates in H3 K36 methylation in vivo. Interestingly, there exist two short amino acid sequences in histone $\mathrm{H} 4$ that are also very similar to the sequence surrounding histone H3 K36 (Fig. 2A). We speculate that either or both of these sequences of histone $\mathrm{H} 4$ participate in Set2-mediated H3 K36 methylation. To test this idea, yeast strains were generated that express $\mathrm{H} 4$ $\Delta \mathrm{G}_{14} \mathrm{AKR}_{17}$ or $\mathrm{H} 4 \Delta \mathrm{G}_{42} \mathrm{VKR}_{45}$ histone mutations. Western blotting analysis shows that cells expressing $\mathrm{H} 4$ $\Delta \mathrm{G}_{14} \mathrm{AKR}_{17}$ have no detectable changes in H3 K36 meth- ylation (Supplemental Fig. S1A). This is consistent with previous published data demonstrating that yeast cells expressing histone $\mathrm{H} 4 \Delta 4-19$ do not noticeably affect global H3 K36 methylation (Fingerman et al. 2007). Cells expressing a histone $\mathrm{H} 4$ mutant lacking amino acids $\mathrm{G}_{42} \mathrm{VKR}_{45}$ are not viable, indicating that one or more residues in this sequence are essential. Thus, we decided to examine the histone methylation status of yeast strains bearing single-point mutations in this region. Although conservative substitutions of histone $\mathrm{H} 4$ at V43 and R45 were viable, cells expressing $\mathrm{H} 4 \mathrm{~V} 43 \mathrm{E}, \mathrm{H} 4$ V43Q, H4 $\Delta$ V43, and H4 R45A were not viable (data not shown). Since H4 R45 protrudes into the minor groove of nucleosomal DNA, it is likely that the lethal mutations disrupt critical histone-DNA contacts needed for in vivo nucleosome formation or higher order chromatin folding (Luger et al. 1997; White et al. 2001; Muthurajan et al. 2004).

The various methylation states of histone $\mathrm{H} 3$ at $\mathrm{K} 4$, $\mathrm{K} 36$, and $\mathrm{K} 79$, in cells expressing histone $\mathrm{H} 4$ mutations that were nonlethal, were examined by Western blots using methyl-specific antibodies. As shown in Figure 2B and Supplemental Figure S1C, global histone H3 K36 trimethylation is not affected by H4 V43A, H4 V43I, and H4 R45K substitutions. Strikingly, histone H3 K36 diand trimethylation is significantly reduced in yeast strains expressing H4 K44Q and almost undetectable in H4 K44E mutants (Fig. 2B). Interestingly, wild-type levels of H3 K36 di- and trimethylation are detected in $\mathrm{H} 4$ K44R, K44A, and K44L (Fig. 2B; Supplemental Fig. S1C). These mutations suggest that a conserved positive charge and/or hydrophobic amino acids are needed in the nucleosome for mediating proper H3 K36 methylation. The impact that H4 K44Q and K44E substitutions has on H3 K36 methylation is specific, as cells expressing these mutants do not show any detectable changes in global
Figure 2. H4 K44 is needed for H3 K36 methylation in vivo and Set2 interaction in vitro. $(A)$ Alignment of amino acid sequences of histone H3 (33-37), histone $\mathrm{H} 4$ (13-17) and histone $\mathrm{H} 4$ (41-45). Identical amino acids are shaded gray. $(B)$ Yeast whole-cell extracts generated from cells expressing wild-type (WT) histones or the indicated histone mutants were immunoblotted with $\mathrm{H} 3 \mathrm{~K} 4, \mathrm{H} 3 \mathrm{~K} 36$, and H3 K79 methyl-specific or $\mathrm{H} 4$ acetylation-specific (H4 Acetyl) antibodies. Immunoblots for histone $\mathrm{H} 3$ and $\mathrm{H} 4$ were used as loading controls. Asterisks indicate a nonspecific band. $(C)$ In vitro HMT assays were performed using yeast chromatin substrates isolated from cells expressing wild-type histones or histone mutants in the absence or presence of recombinant CBP-Set2. HMT reactions were analyzed by filterbinding assays and scintillation counting. $(D)$ In vitro binding assays were performed to examine if Set2 interacts with GST-H4 $4_{24-50}$. Bacterial expressed CBP-Set2 cell extracts were incubated with GST, GST-H4 $4_{24-50}$, or GST-H4 $24-50$ lacking residues $\mathrm{G}_{42} \mathrm{VKR}_{45}\left(\mathrm{GST}-\mathrm{H} 4_{24-50 \Delta \mathrm{GVKR}}\right)$ or GST-H4 $4_{24-50}$ with K44 mutations (K44R, K44Q, and K44E). Bound and input amounts of CBP-Set2 protein were detected by immunoblotting with an anti-CBP antibody. The amount of GST or GST-H4 fusion protein used was analyzed by Coomassie blue staining.

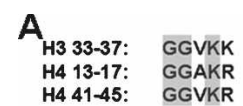

$\begin{array}{lll}\text { H4 13-17: } & \text { GGAKR } \\ \text { H4 41-45: } & \text { GGVKR }\end{array}$

B
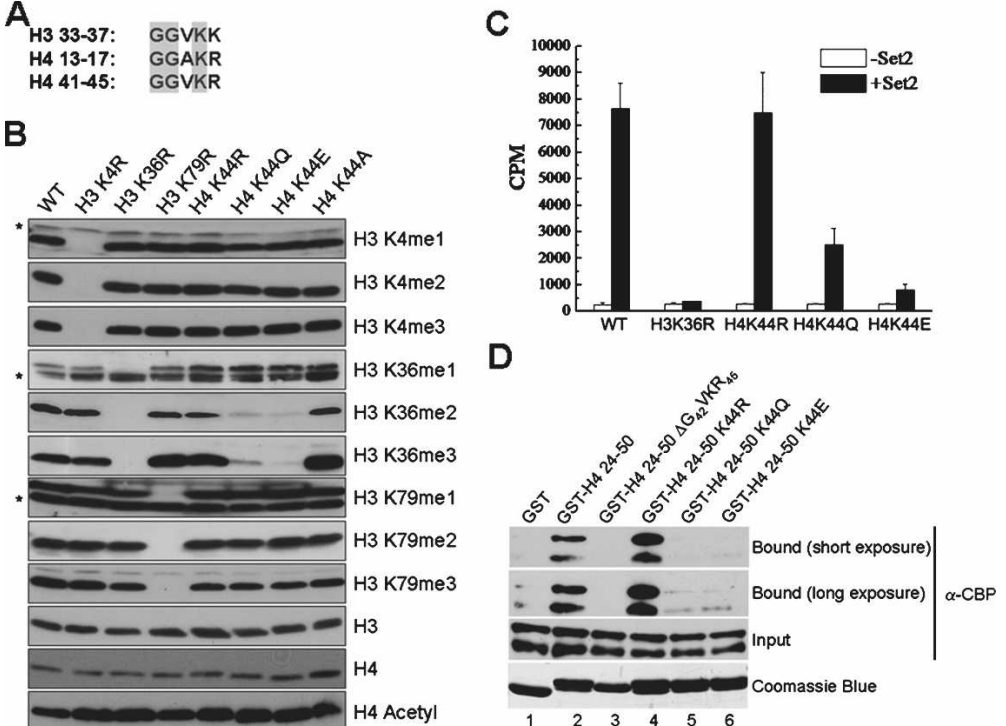
histone H3 K4, H3 K79 methylation or H4 acetylation (Fig. 2B). More importantly, the severe reduction of $\mathrm{H} 3$ $\mathrm{K} 36$ di- and trimethylation in $\mathrm{H} 4 \mathrm{~K} 44 \mathrm{Q}$ and $\mathrm{K} 44 \mathrm{E}$ strains is not a result of lower Set2 protein levels, since immunoblots with anti-Set 2 antibodies show wild-type levels of Set2 protein (Supplemental Fig. S1D).

Since both $\mathrm{H} 4 \mathrm{G}_{14} \mathrm{AKR}_{17}$ and $\mathrm{H}_{4} \mathrm{G}_{42} \mathrm{VKR}_{45}$ are similar sequences, both sequences may be necessary or redundant for histone H3 K36 monomethylation. Therefore, the methyl state of H3 K36 was examined in cells expressing double histone mutants in which a H4 K44Q mutation was combined with a $\mathrm{H}_{4} \mathrm{G}_{14} \mathrm{AKR}_{17}$ deletion or a H4 K16Q mutation. Both double histone mutants show wild-type levels of H3 K36 monomethylation and similar levels of $\mathrm{H} 3 \mathrm{~K} 36 \mathrm{di}$ - and trimethylation relative to the single K44Q mutant (Supplemental Fig. S1A,B). These results suggest that $\mathrm{H} 4 \mathrm{~K} 44$, but not $\mathrm{H} 4 \mathrm{G}_{14} \mathrm{AKR}_{17}$, is important for $\mathrm{H} 3 \mathrm{~K} 36$ di- and trimethylation in vivo.

Since there is a significant disruption of histone $\mathrm{H} 3$ $\mathrm{K} 36$ di- and trimethylation in yeast cells expressing $\mathrm{H} 4$ $\mathrm{K} 44 \mathrm{Q}$ or $\mathrm{K} 44 \mathrm{E}$ mutants, we investigated whether $\mathrm{H} 4$ $\mathrm{G}_{42} \mathrm{VKR}_{45}$ was necessary for Set2 activity on chromatin substrates in vitro. Soluble chromatin substrates were isolated from the nuclei of yeast cells expressing either wild-type or various H4 K44 histone mutants and normalized to similar histone concentrations (Supplemental Fig. S1E). These substrates were incubated with or without recombinant CBP-Set2 protein, and in vitro HMT assays were performed and total ${ }^{3} \mathrm{H}$-methyl incorporation was measured. While Set2 methylates the H4 K44R substrate to a similar degree as wild-type chromatin, a 2.5-fold to threefold decrease or an eightfold decrease in activity was observed on H4K44Q and H4 K44E substrates, respectively (Fig. 2C). Additionally, we saw similar observations in HMT assays using yeast purified wild-type or $\mathrm{H} 4 \mathrm{~K} 44 \mathrm{E}$ core histones as substrates (Supplemental Fig. S2A). Since H4 K44Q and H4 K44E mutants have intact H3 K36 monomethylation in vivo, the remaining Set2 in vitro activity is likely a consequence of H3 K36 monomethylation of unmodified histone H3. Set2 can also in vitro methylate both H4 K44A and H4 K44L chromatin as effectively as wild-type chromatin (data not shown). This is consistent with our in vivo data showing wild-type levels of H3 K36 methylation in cells expressing H4 K44A or H4 K44L (Fig. 2B, Supplemental Fig. S1C). Together, our in vitro and in vivo methylation data demonstrate that histone $\mathrm{H} 4$ plays a critical role in maintaining the proper H3 K36 methylation state. In addition, our results suggest that Set2 may physically interact with histone $\mathrm{H} 4$ to mediate trans-histone H3 K36 di- and trimethylation.

To investigate if Set2 directly interacts with histone $\mathrm{H} 4$, in vitro binding assays were performed using purified GST-H4 fusion proteins, coding for GST-H4 ${ }_{24-50}$ or GST-H4 $4_{24-50}$ lacking $\mathrm{G}_{42} \mathrm{VKR}_{45}$ as well as GST-H4 ${ }_{24-50}$ bearing various $\mathrm{H} 4 \mathrm{~K} 44$ point mutations. Escherichia coli extracts expressing recombinant CBP-Set2 were incubated with the indicated GST-H4 fusion proteins or GST. We observed that Set2 binds to GST-H4 $4_{24-50}$ in vitro, as well as the GST-H4 ${ }_{24-50}$ K44R mutant (Fig. 2D, lanes 2,4). In contrast, Set2 binding to GST-H4 ${ }_{24-50}$ lacking $\mathrm{G}_{42} \mathrm{VKR}_{45}$ is not detectable (Fig. 2D, lane 3, long exposure panel). Importantly, the interactions with Set2 and GST-H4 $4_{24-50}$ are nearly abolished by K44Q and K44E mutations (Fig. 2D, lanes 5,6). These results parallel our in vivo H3 K36 methylation data and demonstrate that histone $\mathrm{H} 4$ mutants that perturb Set2 interactions in vitro have defects in $\mathrm{H} 3 \mathrm{~K} 36$ di- and trimethylation in vivo.

Since all histone $\mathrm{H} 4$ mutant strains that we generated have intact levels of H3 K36 monomethylation, we speculated that Set2 may directly interact with the histone H3 methylation site to mediate K36 monomethylation. To test this idea, we generated GST-H3 $3_{23-50}$ protein that contains a Set2-mediated K36 methylation site. In vitro binding assays showed that, similar to GST-H4 $4_{24-50}$ GST-H3 $3_{23-50}$ also binds to CBP-Set2 (Supplemental Fig. S2B). More importantly, Set2 only associated with unmodified histone H3 K36 peptide, but not any methylated H3 K36 species in vitro (Fig. 3D). Altogether, these results suggest that histone $\mathrm{H} 3$ directs Set2-mediated K36 monomethylation and indicates why Set2 utilizes the positive charged and/or hydrophobic residues in histone $\mathrm{H} 4$ for binding and subsequent H3 K36 di- and trimethylation. How Set2-H3 association affects H3 K36 monomethylation in vivo is under investigation.

\section{The $N$ terminus of Set2 contains a histone H4 interaction motif}

Given that an interaction between Set2 and histone H4 is needed for H3 K36 di- and trimethylation, we sought to identify a corresponding region in Set2 that interacts with histone $\mathrm{H} 4$ directly. Bacterial expression constructs were generated that encoded for various CBP-tagged Set2 truncations. Constructs were engineered to express the $\mathrm{N}$-terminal, middle or C-terminal region of Set 2 based on the predicted secondary structure of Set2 (Fig. 3A). In vitro binding assays were performed using GST-H4 ${ }_{24-50}$, incubated with $E$. coli extracts expressing recombinant CBP-Set $2_{1-261}$, CBP-Set $2_{262-475}$, or CBP-Set $2_{476-733}$, respectively. As shown in Figure $3 \mathrm{~B}$, the $\mathrm{N}$ terminus of Set2 (CBP-Set2 ${ }_{1-261}$ ), but not the middle or $\mathrm{C}$ terminus of Set2, efficiently binds to GST-H4 $4_{24-50}$.

To further characterize the binding site on Set2 important for histone $\mathrm{H} 4$ interaction, two smaller N-terminal truncations of Set2, CBP-Set2 $2_{1-119}$ and CBP-Set2 $2_{120-261}$, were examined for their ability to bind GST-H4 $4_{24-50}$. In vitro binding assays show that the more N-terminal region, CBP-Set $2_{1-119}$, is sufficient for interaction with GST-H4 ${ }_{24-50}$ (Fig. 3C, lane 2 vs. lane 4). Further mutational analysis of the $\mathrm{N}$ terminus of Set2 was done to identify the histone H4-binding site on Set2. As shown in Figure 3C, the very N-terminal fragment, CBP-Set $2_{1-62}$, and CBP-Set2 $1-261 \Delta$ Aws, which lacks the associated with SET (AWS) domain of Set2 (amino acids 63-119), associates with GST-H4 $4_{24-50}$ (Fig. 3C, lane 10 vs. lane 8). The AWS domain is similar to the Pre-SET domain, which is needed for the catalytic activity of SUV39H1 (Rea et al. 2000). Furthermore, CBP-Set2 ${ }_{1-50}$, 
Du et al.
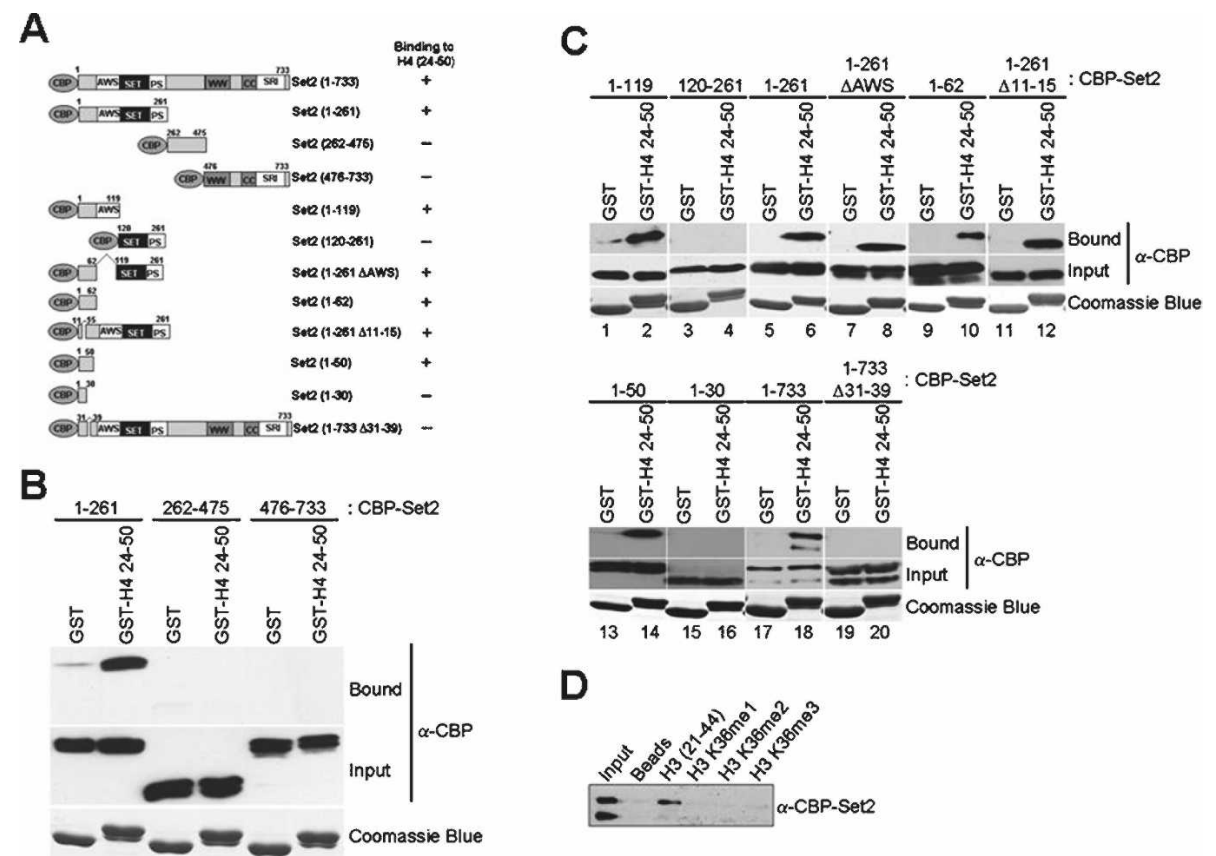

Figure 3. Amino acids 31-39 in the $\mathrm{N}$ terminus of Set 2 contain a histone H4 interaction motif. (A) Schematic representation of CBP-Set2 constructs used for in vitro binding assays. The SET domain (SET) along with the AWS, the post-SET domain (PS), WW domain (WW), coiled-coil motif (CC), and the SRI are shown. (B) The $\mathrm{N}$ terminus of Set2 containing the SET domain binds to GST-H4 ${ }_{24-50}$. Bacterial extracts from cells expressing CBP-Set $2_{1-261}$, CBP-Set $2_{262-475}$, and CBP-Set2 ${ }_{476-733}$ were incubated with GST$\mathrm{H} 4_{24-50}$. (C) Amino acids 31-39 in the N terminus of Set2 interact with GST-H4 ${ }_{24-50}$. Bacterially expressed and purified CBP-Set $2_{1-119}$ CBP-Set $2_{120-261}$, CBP-Set $2_{120-261 \Delta A w s}$, CBP-Set $2_{1-63}$, CBP-Set $2_{1-261 \Delta 11-15}$, CBP-Set $2_{1-50}$, CBP-Set $2_{1-30}$, and CBP-Set $2_{\Delta 31-39}$ were incubated in the presence of GST-H4 $4_{24-50}$ beads. In the in vitro binding assays described in $B$ and $C$, bound and input amounts of CBP-Set2 and CBP-Set 2 mutant protein were detected by immunoblotting with an anti-CBP antibody. The amount of GST or GST-H4 $24-50$ fusion protein used was analyzed by Coomassie blue staining. (D) Set2 binds unmodified H3 K36 peptide. Western blot analysis of CBP-Set2 after pull-down assays using biotinylated histone H3 (21-44), mono-, di-, and trimethyl-histone H3 K36 peptides.

but not CBP-Set $2_{1-30}$, efficiently interacts with GST$\mathrm{H}_{24-50}$, indicating that the histone H4-binding site exists between amino acids 31 and 50 of Set2 (Fig. 3C, lane 14 vs. lane 16$)$.

Upon inspection of this region of Set2, a sequence containing both acidic and hydrophobic residues, $\mathrm{D}_{31}$ QEPDLTEE $_{39}$, was apparent. We hypothesize that this may mediate interactions between Set2 and histone $\mathrm{H} 4$ through a possible charge-based mechanism, similar to what has been observed with Dot1. Therefore, a fulllength CBP-Set2 mutant lacking residue 31-39 (CBPSet $2_{\Delta 31-39}$ ) was generated, and we tested its ability to bind GST-H4 ${ }_{24-50}$. Compared with wild-type Set2, binding of this mutant to GST-H4 $4_{24-50}$ is not detectable (Fig. 3C, lane 18 vs. lane 20), indicating that amino acids $31-$ 39 are the critical residues important for mediating Set2$\mathrm{H} 4$ interactions. We also noticed another acidic patch in Set2, located in the $\mathrm{N}$ terminus, $\mathrm{E}_{11} \mathrm{DEKE}_{15}$, which contained only charged residues. CBP-Set $2_{1-261 \Delta 11-15}$, lacking these five amino acids, was generated and tested in vitro for histone $\mathrm{H} 4$ binding. However, the acid patch mutant of Set2 (CBP-Set2 $2_{1-261 \Delta 11-15}$ ), similar to Set2 ${ }_{1-261}$, was still capable of binding to GST-H4 $4_{24-50}$, suggesting that this stretch of charged residues is not important for histone $\mathrm{H} 4$ interaction (Fig. 3C, lanes 6,12). Overall, these results identified a histone $\mathrm{H} 4$ interaction motif located in the $\mathrm{N}$ terminus of Set2 where both charge and hydrophobic interactions may contribute to binding.

Set2's histone H4 interaction motif is needed for proper H3 K36 di- and trimethylation and binding to nucleosomes.

Since our data imply that the $\mathrm{N}$ terminus of Set 2 containing the histone $\mathrm{H} 4$ interaction motif mediates association with GST-H4 $4_{24-50}$ in vitro, we predict that this motif of Set2 may be important for H3 K36 di- and trimethylation in vivo. Therefore, Set $2 \mathrm{~N}$-terminal deletion constructs containing a single C-terminal HA epitope tag were generated and placed under the control of the Set2 endogenous promoter (Fig. 4A). These constructs were expressed in set $2 \Delta$ cells, and whole-cell extracts were prepared and analyzed for H3 K36 methylation by Western blots. Since the Set2-Rpb1-interacting (SRI) domain of Set2 is required for binding to the phosphorylated CTD of RNAPII and H3 K36 dimethylation (Kizer et al. 2005), a C-terminal deletion construct lacking the SRI domain (Set2-HA ${ }_{1-618}$ ) was included in this assay as a negative control. As shown in Figure 4A, cells expressing Set2- $\mathrm{HA}_{\Delta 31-39}$, a mutant lacking the histone H4 interaction motif, have significantly less detectable 
A

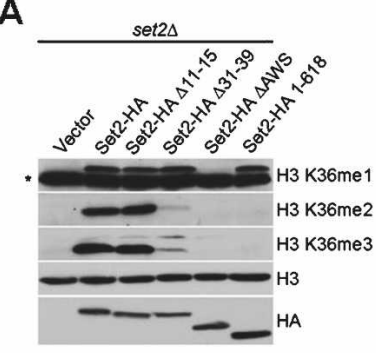

C

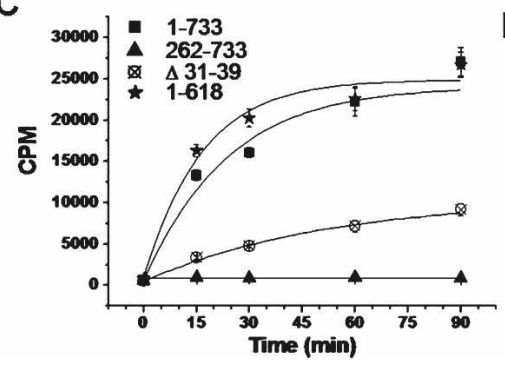

B

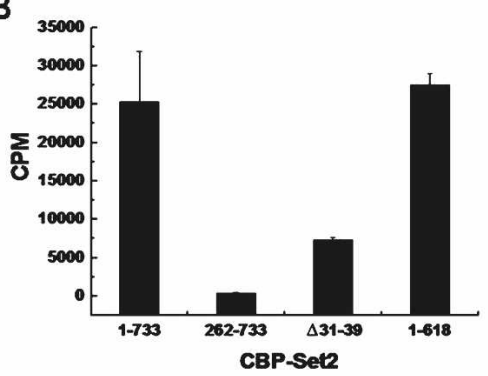

D

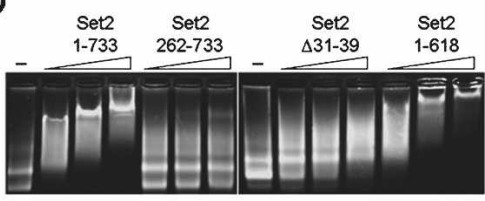

Figure 4. The histone $\mathrm{H} 4$ interaction motif of Set2 is needed for proper H3 $\mathrm{K} 36$ di- and trimethylation and binding nucleosomes. $(A)$ Yeast whole-cell extracts of set2s cells expressing the indicated Set2HA constructs were generated and immunoblotted using the indicated $\mathrm{H} 3 \mathrm{~K} 36$ methyl-specific antibodies. Histone $\mathrm{H} 3$ and Set2-HA proteins were detected by immunoblotting with anti-H3 or anti-HA antibodies. All Set2 constructs were C-terminally tagged with a single HA tag and expressed by the endogenous Set2 promoter. Asterisk indicates a nonspecific band. $(B, C)$ In vitro HMT assays were performed using recombinant-purified CBP-Set $2_{1-733,}$ CBP-Set $2_{262-733}$, CBP-Set $2_{\triangle 31-39}$, or CBP-Set $2_{1-618}$ incubated with chicken nucleosomes and analyzed at various time points. $(D)$ CBP-Set2 proteins described in $B$ were used for nucleosome-binding assays at three different protein concentrations: 1.0, 2.0 , and $4.0 \mu \mathrm{M}$.
H3 K36 di- and trimethylation as compared with cells expressing wild-type Set2-HA. This defect is not a result of the HA tag, as cells expressing Set $2_{\Delta 31-39}$ with a Flag tag have a similar phenotype (Supplemental Fig. S3). As expected, deletion of the AWS region of Set 2 completely abolishes all states of H3 K36 methylation, indicating that Set2-HA $\mathrm{HAws}_{\Delta \mathrm{Acts}}$ as a catalytically inactive mutant. Consistent with our in vitro binding results, we observed that all H3 K36 methylation states are rescued in cells expressing Set2-HA $\mathrm{A}_{\Delta 11-15}$. Importantly, these cells have detectable and similar levels of Set2 as shown by Western blot analysis, excluding the possibility that the observed defects of H3 K36 methylation are due to the loss of Set2 protein (Figs. 4A, 5A; Supplemental Fig. S3). As previously published, a loss of H3 K36 dimethylation was observed in cells expressing a Set2 mutant lacking the SRI domain $\left(\right.$ Set2-HA $\left.{ }_{1-618}\right)$ (Kizer et al. 2005). However, what was surprising but yet not observed before is that wild-type levels of monomethylation still occur in cells expressing the Set2-HA $1-618$ mutant. These results suggest that the recruitment of Set2 by the phosphorylated CTD of RNAPII to target chromatin is not required for H3 K36 monomethylation and establishes the importance of the histone $\mathrm{H} 4$ interaction motif in Set2 for in vivo di- and trimethylation.

Next, we examined whether the Set $2_{\Delta 31-39}$ mutant, which lacked detectable $\mathrm{H} 4$ peptide binding in vitro and $\mathrm{H} 3 \mathrm{~K} 36$ di- and trimethylation in vivo, possesses in vitro HMT activity. Recombinant purified CBP-Set2, CBPSet2 262-733, which lacks the N-terminal SET domain, CBP-Set $2_{\Delta 31-39}$, and CBP-Set $2_{1-618}$ were assayed for HMT activity using chicken erythrocyte nucleosomes as substrates. As shown in Figure 4B, CBP-Set $2_{\Delta 31-39}$ shows almost a fourfold decrease in activity on nucleosomes as compared with wild-type CBP-Set2, whereas the catalytically dead Set2 mutant, CBP-Set $2_{262-733}$, has no detectable activity. Interestingly, CBP-Set2 ${ }_{1-618}$ has wild-type levels of activity in vitro, yet yeast cells expressing the corresponding fragment, Set2-HA $\mathrm{H}_{1-618}$, are unable to di- and trimethylate H3 K36 in vivo. This unexpected in vitro activity of CBP-Set $2_{1-618}$ is not due to uneven amounts of proteins used in the assays, as similar amounts of proteins were used in each reaction. Based on our results, Set2 lacking the SRI domain can efficiently methylate nucleosome substrates and possibly bind nucleosomes in vitro because it still contains the $\mathrm{N}$-terminal histone $\mathrm{H} 4$ interaction motif. In addition, a time-course analysis of the HMT assays was performed on nucleosomal substrates with the indicated Set2 proteins (Fig. 4C). CBP-Set $2_{\Delta 31-39}$ has decreased activity on nucleosomes when compared with wild-type CBP-Set2 at all time points, which is consistent with our observation shown in Figure 4B. This result also suggests that Set2 lacking the histone $\mathrm{H} 4$ interaction motif is probably less active on nucleosomal substrates due to compromised nucleosome binding.

To address these issues, in vitro nucleosome-binding assays were performed using chicken nucleosomes incubated with recombinant, purified Set2 or various Set2 mutant proteins. Wild-type Set 2 and Set $2_{1-618}$ can strongly associate with nucleosomes, while Set $2_{262-733}$ demonstrates a severe reduction in its ability to associate with nucleosomes (Fig. 4D). As predicted, we observe that the histone $\mathrm{H} 4$ interaction motif mutant $\left(\operatorname{Set} 2_{\Delta 31-39}\right)$ was less efficient in binding nucleosomes, as compared with wild-type Set 2 or with a Set 2 mutant lacking the SRI domain. Together, these results indicate that the $\mathrm{N}$ terminus of Set2 that contains the histone $\mathrm{H} 4$ interaction motif is critical for proper nucleosome binding and needed for full in vitro methyltransferase activity on nucleosomal substrates. These results also help explain why the Set 2 mutant lacking the SRI domain, Set $2_{1-618}$ is fully competent to methylate nucleosomal substrates in vitro but not in vivo. 
Figure 5. Set2 lacking the histone $\mathrm{H} 4$ interaction motif is targeted to gene-specific loci by associating with the phosphorylated CTD of RNAPII. (A) Yeast set2s cells were transformed with empty vector or the indicated Set2-3XFlag plasmid constructs. Whole-cell extracts were prepared and immunoprecipitated with the $\alpha$-Flag antibody followed by immunoblot analysis with the H5 $[\alpha$-Ser2P] or H14 [ $\alpha$-Ser5P] antibodies. All input extracts showed similar levels of Set2 as indicated by an $\alpha$-Flag immunoblot. (B) The Ctk1 complex does not regulate Set2-mediated H3 K36 monomethylation in vivo. Whole-cell extracts prepared from wild-type or ctk1 $1 \Delta, c t k 2 \Delta$, and $c t k 3 \Delta$ strains were immunoblotted with H3 K36 methyl-specific antibodies. Immunoblots histone $\mathrm{H} 3$ serve as a loading control. Asterisk indicates a nonspecific band. $(C)$ The indicated Set2 strains were examined for H3 K36 trimethylation, H4 acetylation, and the presence of Set2 at STE11 and FLO8 loci by ChIP. Input and histone H3 levels were used as loading controls.

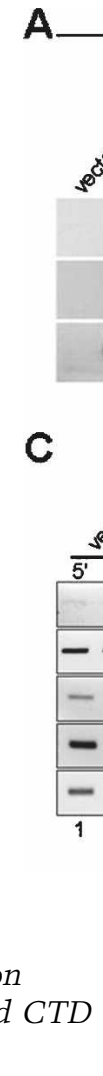
motif can still associate with the phosphorylated CTD of RNAPII

As shown in Figure 4A, cells expressing Set2-HA $\mathrm{H}_{\Delta 31-39}$ and Set2- $\mathrm{HA}_{1-618}$ show significant defects of $\mathrm{H} 3 \mathrm{~K} 36$ diand trimethylation. It has been indicated that the C-terminal SRI domain of Set2 binds to the phosphorylated CTD of RNAPII in vivo, and this association is required for H3 K36 dimethylation (Xiao et al. 2003). Therefore, the histone $\mathrm{H} 3 \mathrm{~K} 36$ di- and trimethylation defects that occur in a Set $2_{\Delta 31-39}$ mutant could be a consequence of disrupting interactions between Set2 and the phosphorylated CTD of RNAPII. To determine if this is occurring, vector, full-length Set2-3XFlag ${ }_{1-733}$, Set2-3XFlag ${ }_{\Delta 31-39 \text {, }}$ or Set2-3XFlag ${ }_{1-618}$ constructs were expressed in set2s cells, and whole-cell extracts were prepared for coimmunoprecipitation (co-IP) experiments. Consistent with previous results, full-length Set2 efficiently binds to the phosphorylated CTD as detected by the Ser2 or Ser5 phospho-specific CTD antibodies, whereas Set $2_{1-618}$ is unable to coimmunoprecipitate with the CTD (Fig. 5A). Noticeably, Set $2_{\Delta 31-39}$ still binds to the CTD, which suggests that deletion of the histone $\mathrm{H} 4$ interaction motif of Set2 does not interfere with the association of Set2 and the phosphorylated CTD of RNAPII. This indicates that Set2 lacking the histone $\mathrm{H} 4$ interaction motif $\left(\operatorname{Set}_{\triangle 31-39}\right)$ is still recruited to chromatin by RNAPII but cannot properly methylate histones due to its inability to interact with histone $\mathrm{H} 4$.

\section{Ctk1 is not required for H3 K36 monomethylation}

Previous reports have indicated that Ctk1 kinase and its associated subunits, Ctk2 and Ctk3, regulate global H3
B
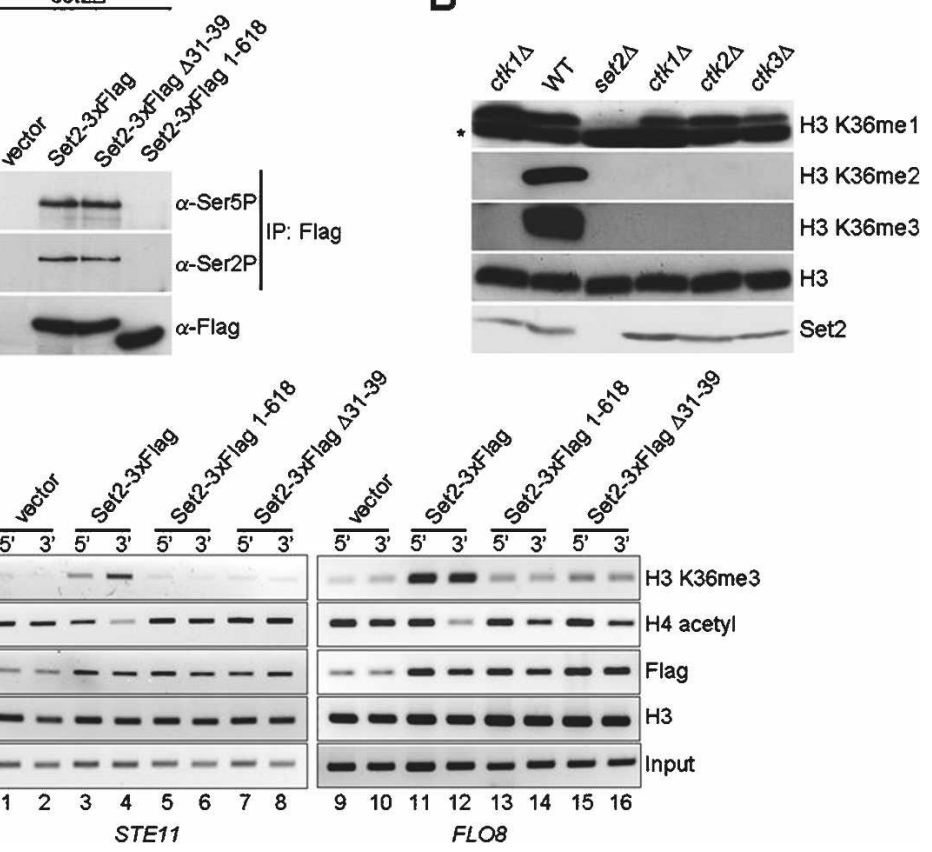

K36 methylation (Xiao et al. 2003; Chu et al. 2006). This occurs through mediating Set 2 recruitment by association with the Ctk1-phosphorylated CTD of RNAPII (Li et al. 2002, 2003; Krogan et al. 2003; Xiao et al. 2003). Additionally, another study has also shown that $c t k 1 \Delta$ cells lack all detectable H3 K36 mono-, di-, and trimethylation (Chu et al. 2006). Given that H3 K36 monomethylation is still observed in Set2 mutants lacking the histone $\mathrm{H} 4$ interaction motif $\left(\mathrm{Set}_{\Delta 31-39}\right)$ or the SRI domain (Set $\left.2_{1-618}\right)$, we wanted to re-examine if Ctk1 regulates H3 K36 monomethylation. Whole-cell extracts isolated from wild-type, ctk $1 \Delta, c t k 2 \Delta$, or ctk $3 \Delta$ strains were analyzed by Western blot to examine H3 K36 mono-, di-, and trimethylation. Deletion of any subunits of the Ctk1 complex (Ctk1, Ctk2, and Ctk3) completely abolishes diand trimethylation, but retains monomethylation (Fig. $5 \mathrm{~B})$. The methylation defect is not due to the loss of Set2 protein in $c t k \Delta$ cells (Fig. 5B). These results suggest that Ctk1 kinase plays a major role in regulating Set2-mediated H3 K36 di- and trimethylation but not H3 K36 monomethylation. Because H3 K36 monomethylation is present in $c t k 1, c t k 2$, and $c t k 3$ deletion mutants and set2 mutants lacking the SRI domain or the histone H4 interaction motif, we speculate that Set2 utilizes another pathway to monomethylate chromatin that does not require association with the phosphorylated CTD of RNAPII. How Set2 is recruited and engages chromatin to generate monomethylation is unclear and under current investigation.

Gene-specific chromatin modifications and targeting of Set2

We showed that the Set2 mutant lacking the histone $\mathrm{H} 4$ interaction motif $\left(\operatorname{Set} 2_{\Delta 31-39}\right)$ can be targeted to chroma- 
tin by RNAPII. However, we also wanted to examine if Set 2 can still be recruited to transcribed regions of active genes. To address this, chromatin immunoprecipitation (ChIP) assays were performed using the strains expressing wild-type Set2, Set $2_{\Delta 31-39}$, and Set $2_{1-618}$. The STE11 and FLO8 loci, which are genes known to undergo cryptic transcription in the absence of Set2, were examined (Carrozza et al. 2005). As expected, a loss of H3 K36 trimethylation was observed at these loci in $\operatorname{set} 2 \Delta$, Set $2_{1-618}$, and Set $2_{\Delta 31-39}$ strains (Fig. 5C). Interestingly, there were no obvious defects of targeting Set $2_{\Delta 31-39}$ and Set $2_{1-618}$ at these two loci. Our data suggest that the H4-binding motif in Set2 associates with RNAPII and is targeted to gene-specific loci but is unable to efficiently catalyze H3 K36 di- and trimethylation. In addition, our results suggest that Set2 lacking the SRI domain (Set2 $1-618$ ) is recruited to genes independent of the phosphorylated CTD of RNAPII (Fig. 5C). Moreover, deletion of Set2 or Set2 mutants with H3 K36 methyl defects increased H4 acetylation in transcribed regions at these loci, suggesting cryptic transcription is occurring.

\section{Disrupting Set2 interactions with histone H4 increases resistance to 6-AU}

Several reports have shown that Set2 plays an important role in transcription elongation through its association with RNAPII (Li et al. 2002, 2003; Krogan et al. 2003; Xiao et al. 2003). Furthermore, this function of Set 2 has been linked with H3 K36 methylation (Kizer et al. 2005). Yeast mutants that are sensitive to the drug 6-AU have been widely used as an indicator to identify protein factors needed for positive transcription elongation in yeast (Exinger and Lacroute 1992). In contrast, set2s and H3 K36R cells exhibit increased resistance to 6-AU, implicating Set2-mediated methylation in events that are antagonistic to transcription elongation (Li et al. 2003; Kizer et al. 2005; Biswas et al. 2006). To examine whether the association of Set 2 with histone $\mathrm{H} 4$ would cause a 6-AU resistance phenotype, cells expressing wild-type histones or various histone mutations were grown on plates with or without 6-AU. The 6-AU phenotype of each strain was monitored after $2 \mathrm{~d}$ of growth. As expected, cells expressing H3 K36R or lacking Set2 exhibited a resistant phenotype (Fig. 6A, rows 2,4). Moreover, H4 K44Q and H4 K44E mutants, which have H3 K36 diand trimethylation defects, also exhibited resistance to 6-AU as compared with wild-type cells (Fig. 6A, row 6; data not shown). Cells expressing H4 K44R that have intact H3 K36 methylation do not show a 6-AU resistant phenotype (Fig. 6A, row 5). These results suggest that cells expressing H4 K44Q mutants that disrupt H3 K36 di- and trimethylation behave similarly to cells lacking all H3 K36 methylation.

Second, we examined if the histone $\mathrm{H} 4$ interaction motif of Set2 (Set2 $\left.{ }_{\Delta 31-39}\right)$ is also needed to maintain proper sensitivity to 6-AU. Yeast set2 $\Delta$ cells expressing wild-type Set2 or various Set2 deletion mutants were tested for 6-AU resistance. Consistent with previous reports, we observed that expression of full-length Set2 or
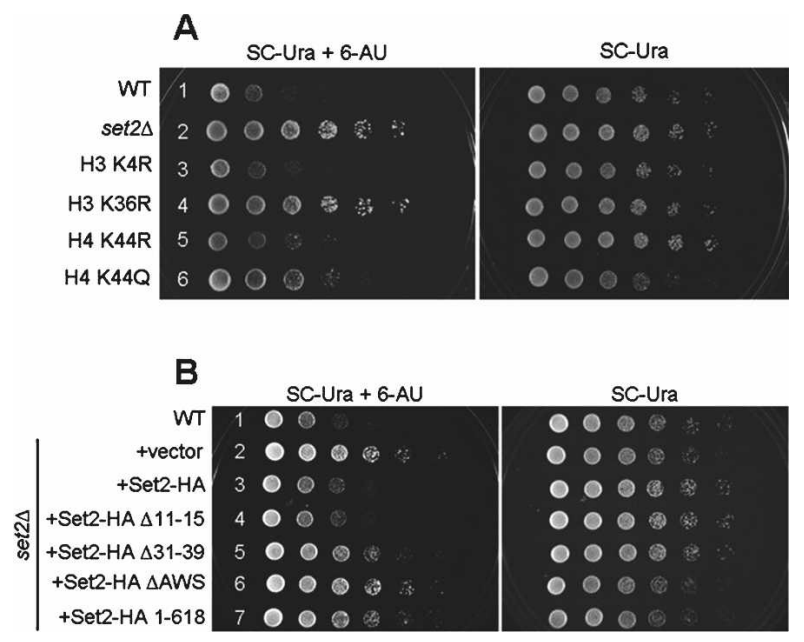

Figure 6. Defects in Set2-mediated H3 K36 di- and trimethylation increase resistance to 6-AU. (A) Cells with H3 K36 methylation defects exhibit 6-AU resistance. Yeast cells expressing wild-type histones or the indicated histone mutants were assayed for growth in the presence or absence of 6-AU (150 $\mathrm{\mu g} /$ $\mathrm{mL})$. (B) Set2 mutant strains that have H3 K36 methylation defects exhibit 6-AU resistance. Yeast cells expressing wildtype or Set 2 mutant strains were assayed for growth in the presence or absence of 6 -AU $(150 \mu \mathrm{g} / \mathrm{mL})$. A Set2 deletion strain (set2 $\Delta$ ) was used in $A$ and $B$ for a positive control for 6-AU resistance.

Set $2_{\Delta 11-15}$, which has no detectable H3 K36 methyl defects, in a set $2 \Delta$ strain restored wild-type levels of 6 -AU sensitivity (Fig. 6B, rows 3,4$)$. In contrast, set $2 \Delta$ cells expressing Set2-HA ${ }_{\Delta 31-39}$, which show defects in H3 K36 di- and trimethylation, exhibited resistance to 6-AU, similar to the phenotype of set2 $\Delta$ cells expressing vector, Set2-HA ${ }_{\Delta \text { Aws, }}$ or Set2-HA $1-618$ (Fig. 6B, rows 2,5,6,7). These data complement the 6-AU phenotype that we observed with cells expressing a H4 K44Q mutant and again suggest that Set2 association with histone $\mathrm{H} 4$ is functionally important in maintaining proper histone H3 K36 methylation and chromatin states during transcription elongation.

\section{Discussion}

In this report, we uncovered a new mechanism for the regulation of $\mathrm{H} 3 \mathrm{~K} 36$ methylation, which is mediated by a trans-histone pathway. Interestingly, this trans-histone pathway is mediated by a conserved lysine residue (H4 K44) in histone $\mathrm{H} 4$ and a histone $\mathrm{H} 4$ interaction motif in the $\mathrm{N}$ terminus of Set2. Our in vivo results also suggest that a Set2-histone H4 interaction must be established to appropriately catalyze H3 K36 di- and trimethylation even after Set2 is appropriately targeted to chromatin by RNAPII. Finally, we show that mutants that disrupt the Set2 and histone $\mathrm{H} 4$ interaction and $\mathrm{H} 3$ $\mathrm{K} 36$ di- and trimethylation show increased $\mathrm{H} 4$ acetylation and resistance to 6-AU suggesting this interaction is needed for appropriate transcription elongation. Alto- 
Du et al.

gether, this study adds to and supports our current understanding of Set2-mediated methylation in transcriptional elongation.

\section{Structural determinants and regulation} of Set2-mediated H3 K36 methylation

The yeast and human crystal structure of the nucleosome reveals that $\mathrm{H} 4 \mathrm{~K} 44$ exists at the loop region linking $\alpha$-helix 1 and $\alpha$-helix 2 of histone $\mathrm{H} 4$, which located near the entry and exit point of the nucleosomal DNA (Fig. 7A,B; Supplemental Fig. S4). In addition, the side chain of $\mathrm{H} 4 \mathrm{~K} 44$ appears to be surrounded by the $\mathrm{C}$ terminus of H2A (Fig. 7A,B; Luger et al. 1997; White et al. 2001). However, if the H2A-H2B dimer is removed from the nucleosome structure, the H4 K44 site becomes more exposed (Fig. 7B). Given that Set2 is associated with the phoshorylated CTD of RNAPII during tran- scription elongation, there is a possibility that Set 2 could bind histone $\mathrm{H} 4$ after $\mathrm{H} 2 \mathrm{~A}-\mathrm{H} 2 \mathrm{~B}$ dimers are removed or before they are reassembled. Alternatively, the H2A C terminus could also contribute to Set2 binding to the nucleosome.

In the human nucleosome crystal structure, histone H3 K36 is positioned between the two strands of nucleosomal DNA near the entry and exit points of the nucleosomal DNA (Supplemental Fig. S4C,D). Based on these structural features, it is not absolutely apparent how Set 2 would bind to histone H4 and methylate H3 K36. However, Set 2 could interact with histone $\mathrm{H} 4$ and wrap around the nucleosomal DNA to methylate H3 K36 within the same nucleosome. These interactions could explain why Set2 preferentially methylates nucleosomes. Our results suggest that Set2 uses multiple contacts to methylate nucleosomes, and additional structural analysis will be necessary to determine precisely how Set2 engages nucleosomes.
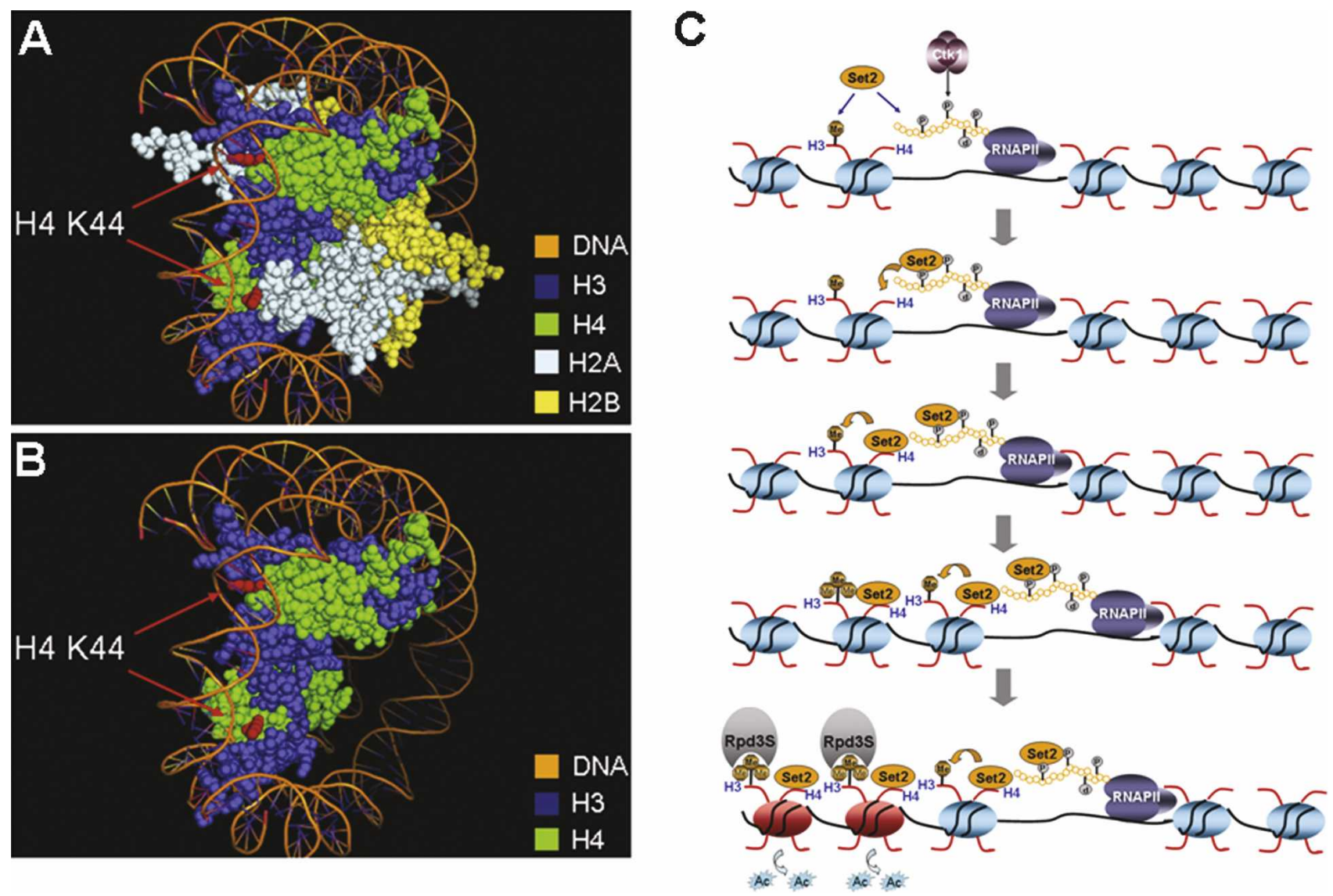

Figure 7. Location of $\mathrm{H} 4 \mathrm{~K} 44$ within the nucleosome and a step-wise model of Set2-mediated methylation. $(A)$ The structure of the yeast nucleosome core particle: Histone H4 (green), Histone H3 (blue), H2A (gray), H2B (yellow), and DNA (orange). The crystal structure of the yeast nucleosome shows that $\mathrm{H} 4 \mathrm{~K} 44$, marked in red, is located in the L1 loop region linking $\alpha$-helix 1 and $\alpha$-helix 2 of H4. (B) The structure of H3/H4 heterotetramer in the absence of H2A and H2B. (C) A step-wise model of Set2-mediated H3 K36 methylation. During transcription elongation, the CTD of RNAPII is phosphorylated by Ctk1 kinase. The SRI domain in the C terminus of Set2 binds to the phosphorylated CTD of RNAPII and recruits Set2 to the 3' ends of ORFs. Once Set2 is recruited to chromatin, the N-terminal histone H4 interaction motif of Set2 will dock on chromatin by binding histone H4, allowing Set2 to efficiently di- and trimethylate H3 K36. After H3 K36 methylation, the Rpd3S complex is recruited to deacetylate histone H3 and H4 to prevent cryptic intragenic transcription. Blue nucleosomes represent acetylated histones and red nucleosomes represent deacetylated histones. 
Two amino acids, H4 V43 and H4 R45, in the sequence cassette surrounding $\mathrm{H} 4 \mathrm{~K} 44$ are considered $\sin ^{-}$mutants when mutated to H4 V43I, H4 R45H, or H4 R45C. These histone $\mathrm{H} 4$ mutants are called $\sin ^{-}$mutants because they can alleviate the transcriptional defects that occur when the chromatin remodeling factor SWI/SNF is inactivated. Although H4 K44 mutants have not been identified as $\sin ^{-}$mutants, they have a slow growth phenotype similar to known $\sin ^{-}$mutants (Kruger et al. 1995; Fry et al. 2006). However, our results would suggest that viable $\sin ^{-}$mutants do not have major defects in H3 K36 methylation (Supplemental Fig. S1C; data not shown). Apparently, sin ${ }^{-}$mutants that are viable have moderate effects on the global structure of the nucleosome but show defects in higher-order chromatin folding (Wechser et al. 1997; Horn et al. 2002; Muthurajan et al. 2004). Therefore, histone H4 K44 mutations that disrupt H3 K36 methylation are probably not causing major structural changes in the nucleosome but could be disrupting higher-order chromatin folding.

Three similar sequences cassettes exist in histone $\mathrm{H} 3$ and $\mathrm{H} 4$ that could serve as putative methylation sites for Set2 (Fig. 2A). Although our results show that Set2 can bind to histone H4, Set2 appears to only methylate H3 K36. Therefore, sequences surrounding H3 K36 $\left(\mathrm{G}_{34} \mathrm{GVK}_{36} \mathrm{KPHR}_{40}\right)$ may affect Set2 recognition and subsequent methylation. For example, H3 P38 has been shown to be a critical residue for regulating $\mathrm{H} 3$ K36 methylation in cis (Nelson et al. 2006). Interestingly, a proline residue does not exist in either of the $\mathrm{H} 4$ sequences surrounding $\mathrm{H} 4 \mathrm{~K} 16\left(\mathrm{G}_{13} \mathrm{GAK}_{\mathbf{1 6}} \mathrm{RHRK}_{20}\right)$ or H4 K44 $\left(\mathrm{G}_{41} \mathrm{GVK}_{\mathbf{4}} \mathrm{RISG}_{48}\right)$. Therefore, a proline residue may be at least one key feature that is needed for Set2 to discriminate what substrate it methylates. An intriguing possibility is that H3 P38 is a major determinant for mediating H3 K36 monomethylation and therefore the reason that Set 2 has to utilize histone $\mathrm{H} 4$ to catalyze subsequent H3 K36 di- and trimethylation.

Besides sequence-specific determinants, covalent modifications may act in cis to regulate H3 K36 methylation and/or prevent methylation on $\mathrm{H} 4 \mathrm{~K} 16$ or $\mathrm{H} 4$ K44. In addition, H4 K16 and H3 K36 are also sites for histone acetylation that would directly prevent methylation from occurring (Suka et al. 2002; Shogren-Knaak and Peterson 2006; Morris et al. 2007). Since two of the three similar sequence cassettes are acetylated, an intriguing possibility is that $\mathrm{H} 4 \mathrm{~K} 44$ is acetylated in vivo to regulate Set2 binding with chromatin. However, current studies mapping histone modifications by mass spectrometry have not identified H4 K44 acetylation or other modifications occurring on this residue (Garcia et al. 2007; Jiang et al. 2007). Finally, it is possible that Set2 or another histone methyltransferase can methylate these sites in vivo, but they still await identification. With the exciting era of proteomics and better mass spectrometry technology, other modifications occurring on these residues may become apparent in time and further our understanding how chromatin is cis- and transregulated.
Histone methyltransferases that utilize trans-histone pathways

Histone lysine methylation is a unique post-translational modification since it can exist in three different methyl states (mono-, di-, and trimethyl). In Saccharomyces cerevisiae, all three methyl states are catalyzed by the same enzyme. Our results show for the first time that Set2-mediated methylation requires a trans-histone mechanism (i.e., requiring more than one histone) to properly catalyze di- and trimethylation. Recently, a similar but distinct trans-histone mechanism was identified for Dot1-mediated H3 K79 di- and trimethylation. In the Dot1-mediated trans-histone methylation pathway, a charge-based interaction occurs between an acid patch in the $\mathrm{C}$ terminus of Dot 1 and the basic patch of histone H4. This charge-based interaction is required for H3 K79 di- and trimethylation but not for H3 K4 methylation or H3 K36 methylation (Fingerman et al. 2007).

In contrast, the Set2-mediated trans-histone methylation pathway seems to require both positively charged and hydrophobic residues in histone $\mathrm{H} 4$ and the newly identified histone H4 interaction motif of Set2. In addition, our studies determine that recruitment of Set 2 by RNAPII is not sufficient to mediate H3 K36 di- and trimethylation on chromatin until Set 2 properly engages histone $\mathrm{H} 4$. Our results are also the first to indicate that H3 K36 monomethylation is recruited to chromatin independent of the Ctk1 kinase and the phosphorylated CTD of RNAPII. Therefore, another pathway, which is needed to recruit Set2-mediated monomethylation to chromatin, is likely to be discovered in the future. An interesting possibility is that monomethylation is catalyzed before histone deposition. Finally, similar but distinct trans-histone methylation pathways that we identified in yeast may also be a mechanism utilized by mammalian methyltransferases.

\section{A step-wise model of H3 K36 methylation and preventative maintenance of the genome}

From our current understanding of Set2-mediated methylation and the results from this study, a step-wise model can be depicted where phosphorylation of the CTD of RNAPII by the Ctk1 complex allows recruitment of Set2 to chromatin (Fig. 7C; Xiao et al. 2003). Upon recruitment, Set 2 must engage chromatin through histone $\mathrm{H} 4$ binding for subsequent H3 K36 di- and trimethylation. Once H3 K36 di- and trimethylation is established, these methyl groups provide binding sites for the Rpd3S complex to cis- and trans-deacetylate histones (Carrozza et al. 2005; Joshi and Struhl 2005; Keogh et al. 2005). All together, these steps help to establish a repressive chromatin behind the elongating RNAPII to prevent spurious intragenic transcription (Carrozza et al. 2005; Li et al. 2007b). This pathway is also particularly needed for long ORFs and infrequently transcribed genes ( $\mathrm{Li}$ et al. 2007b). In summary, we suggest trans-histone methylation and other cis- and trans-histone pathways are critical events that are needed for the preventative mainte- 
nance of the genome so that genome integrity is maintained and detrimental consequences are avoided.

\section{Materials and methods}

\section{Yeast plasmids and strains}

Plasmids and strains used in this study are listed in Supplemental Tables S1-S3. See the Supplemental Material for details describing plasmids and strains.

Preparation of yeast whole-cell extracts, Western blot analysis, and antibodies

Yeast whole-cell extracts were prepared following the procedure as described previously (Fingerman et al. 2005). SDS-PAGE and Western blot analyses were performed as described previously (Briggs et al. 2001). See the Supplemental Material for antibodies used.

Cloning, expression, and purification of Set2 proteins

See the Supplemental Material for details.

\section{In vitro H4-binding assay}

Bacterial cells expressing GST-H4 $4_{24-50}$ fusion proteins were lysed and supernatants were incubated with $10 \mu \mathrm{L}$ of glutathione agarose with rotation for $1 \mathrm{~h}$ at $4^{\circ} \mathrm{C}$. After extensive washing, GST-H4 $4_{24-50}$ bound beads were resuspended in $25 \mu \mathrm{L}$ of lysis buffer, and $1 \mu \mathrm{L}$ of each final slurry was analyzed by SDSPAGE for normalizing protein levels. The remaining GST-H4 $4_{24-50}$ bound agarose beads were incubated with similar amounts of CBP-tagged full-length Set2 or truncated proteins lysates in a final reaction volume of $200 \mu \mathrm{L}$. Binding reactions were incubated with rotation for $2 \mathrm{~h}$ at $4^{\circ} \mathrm{C}$. After washing, $10 \mu \mathrm{L} 2 \times$ SDS-PAGE sample buffer was added to each sample. All samples were analyzed by immunoblotting with an anti-CBP antibody.

\section{In vitro HMT assays}

Recombinant purified CBP-Set2 $(1.0 \mu \mathrm{g})$ was incubated with the following substrates: $2 \mu \mathrm{g}$ of purified chicken nucleosomes, $1 \mu \mathrm{g}$ of recombinant, purified histone $\mathrm{H} 3,1 \mu \mathrm{g}$ of recombinant, purified histone $\mathrm{H} 4$, or a 1:1 mixture of recombinant histone $\mathrm{H} 3$ and $\mathrm{H} 4$ along with $1.0 \mu \mathrm{Ci}$ of $S$-adenosyl-L-[methyl- $\left.{ }^{3} \mathrm{H}\right]$ methionine for $30 \mathrm{~min}$ at $30^{\circ} \mathrm{C}$ in a total volume of $20 \mu \mathrm{L}$. Half of the reaction mixture was used for liquid scintillation counting; the remaining half was analyzed by SDS-PAGE followed by Coomassie blue staining and fluorography. Chromatin substrates were prepared as described previously (Fingerman et al. 2007).

\section{Biotin-labeled histone peptide pull-down assays}

Biotinylated histone H3 (21-44), mono-, di-, and trimethyl-histone H3 K36 peptides were used for Set2 pull-down assays and performed as described by Shi et al. (2006). One microgram of biotinylated unmodified and methylated histone peptides was incubated with $3 \mu \mathrm{g}$ of recombinant purified CBP-Set2 in binding buffer $(50 \mathrm{mM}$ Tris at $\mathrm{pH} 7.4,150 \mathrm{mM} \mathrm{NaCl}, 0.05 \% \mathrm{NP}-40$, $1 \mathrm{mM}$ PMSF) overnight at $4^{\circ} \mathrm{C}$. After $1 \mathrm{~h}$ of incubation, streptavidin beads were washed three times on ice and analyzed.

\section{Nucleosome-binding assay}

Nucleosome-binding assays were performed as described previously (Fingerman et al. 2007). Increasing amounts of recombinant purified CBP-Set 2 protein were incubated with purified chicken mononucleosomes using the same conditions as described in the in vitro HMT assay. After incubation for $1 \mathrm{~h}$ at $30^{\circ} \mathrm{C}$, samples were resolved on a $2.0 \%$ agarose gel and visualized under UV light by ethidium bromide staining.

\section{Immunoprecipitations}

Set 2 deletion $(\operatorname{set} 2 \Delta)$ cells were transformed with the indicated series of Set2 expression constructs and grown to an $\mathrm{OD}_{600}$ of $\sim 0.8,50 \mathrm{~mL}$ cultures were harvested, and whole-cell extracts were prepared. Co-IP experiments were performed in a final volume of $0.9 \mathrm{~mL}$. The extracts were incubated with $12.5 \mu \mathrm{L}$ of pre-equilibrated anti-Flag M2 affinity beads for $2 \mathrm{~h}$ at $4^{\circ} \mathrm{C}$, after which extracts were washed three times for 2 min in extraction buffer. The beads were eluted in SDS-PAGE loading buffer, and bead-bound proteins were analyzed by immunoblotting with antibodies directed against the phospho-CTD of RNAPII.

\section{ChIPs}

The ChIP assays were performed as described previously (Kuo and Allis 1999). See the Supplemental Material for details and primer sequences.

\section{6-AU growth assay}

Yeast strains WZY42 or BY4741 expressing the histone mutants or various Set2 mutants were transformed with pRS416 (URA3, $C E N)$ and grown in synthetic complete drop-out medium lacking uracil (SC-Ura). Overnight cultures were diluted to an $\mathrm{OD}_{600}$ of 0.1 and regrown to an $\mathrm{OD}_{600}$ of 0.8 , and fivefold serial dilutions were plated on SC-Ura plates with or without 6-AU (Sigma). Cells were grown $1-2 \mathrm{~d}$ at $30^{\circ} \mathrm{C}$ before plates were photographed.

\section{Acknowledgments}

We thank Dr. Brian Strahl for providing the Set2 antibody and Set2-Flag yeast strain, Dr. Or Gozani for H3 K36me2 and H3 K36me3 histone peptides, Dr. Peter Cheung for critically reading our manuscript, Dr. Hui-Chun Li for generating various plasmid constructs, and Adam Henry for purified yeast histones. The Purdue University Agricultural Experiment Station number is $2008-18368$. This research was supported by a grant from the National Institutes of Health to S.D.B. (GM74183).

\section{References}

Altaf, M., Utley, R.T., Lacoste, N., Tan, S., Briggs, S.D., and Cote, J. 2007. Interplay of chromatin modifiers on a short basic patch of histone $\mathrm{H} 4$ tail defines the boundary of telomeric heterochromatin. Mol. Cell 28: 1002-1014.

Biswas, D., Dutta-Biswas, R., Mitra, D., Shibata, Y., Strahl, B.D., Formosa, T., and Stillman, D.J. 2006. Opposing roles for Set2 and $\mathrm{yFACT}$ in regulating TBP binding at promoters. $E M B O$ J. 25: 4479-4489.

Briggs, S.D., Bryk, M., Strahl, B.D., Cheung, W.L., Davie, J.K., Dent, S.Y., Winston, F., and Allis, C.D. 2001. Histone H3 lysine 4 methylation is mediated by Set 1 and required for cell growth and rDNA silencing in Saccharomyces cerevi- 
siae. Genes \& Dev. 15: 3286-3295.

Briggs, S.D., Xiao, T., Sun, Z.W., Caldwell, J.A., Shabanowitz, J., Hunt, D.F., Allis, C.D., and Strahl, B.D. 2002. Gene silencing: Trans-histone regulatory pathway in chromatin. Nature 418: 498.

Carrozza, M.J., Li, B., Florens, L., Suganuma, T., Swanson, S.K., Lee, K.K., Shia, W.J., Anderson, S., Yates, J., Washburn, M.P., et al. 2005. Histone H3 methylation by Set 2 directs deacetylation of coding regions by Rpd3S to suppress spurious intragenic transcription. Cell 123: 581-592.

Chu, Y., Sutton, A., Sternglanz, R., and Prelich, G. 2006. The BUR1 cyclin-dependent protein kinase is required for the normal pattern of histone methylation by SET2. Mol. Cell. Biol. 26: 3029-3038.

Dover, J., Schneider, J., Tawiah-Boateng, M.A., Wood, A., Dean, K., Johnston, M., and Shilatifard, A. 2002. Methylation of histone $\mathrm{H} 3$ by COMPASS requires ubiquitination of histone H2B by Rad6. J. Biol. Chem. 277: 28368-28371.

Exinger, F. and Lacroute, F. 1992. 6-Azauracil inhibition of GTP biosynthesis in Saccharomyces cerevisiae. Curr. Genet. 22: 9-11.

Fingerman, I.M., Wu, C.L., Wilson, B.D., and Briggs, S.D. 2005. Global loss of Set1-mediated H3 Lys4 trimethylation is associated with silencing defects in Saccharomyces cerevisiae. J. Biol. Chem. 280: 28761-28765.

Fingerman, I.M., Li, H.C., and Briggs, S.D. 2007. A charge-based interaction between histone $\mathrm{H} 4$ and Dot 1 is required for H3K79 methylation and telomere silencing: Identification of a new trans-histone pathway. Genes \& Dev. 21: 2018-2029.

Fischle, W., Wang, Y., and Allis, C.D. 2003. Histone and chromatin cross-talk. Curr. Opin. Cell Biol. 15: 172-183.

Fry, C.J., Norris, A., Cosgrove, M., Boeke, J.D., and Peterson, C.L. 2006. The LRS and SIN domains: Two structurally equivalent but functionally distinct nucleosomal surfaces required for transcriptional silencing. Mol. Cell. Biol. 26: 9045-9059.

Garcia, B.A., Hake, S.B., Diaz, R.L., Kauer, M., Morris, S.A., Recht, J., Shabanowitz, J., Mishra, N., Strahl, B.D., Allis, C.D., et al. 2007. Organismal differences in post-translational modifications in histones $\mathrm{H} 3$ and H4. J. Biol. Chem. 282: 7641-7655.

Horn, P.J., Crowley, K.A., Carruthers, L.M., Hansen, J.C., and Peterson, C.L. 2002. The SIN domain of the histone octamer is essential for intramolecular folding of nucleosomal arrays. Nat. Struct. Biol. 9: 167-171.

Jiang, L., Smith, J.N., Anderson, S.L., Ma, P., Mizzen, C.A., and Kelleher, N.L. 2007. Global assessment of combinatorial post-translational modification of core histones in yeast using contemporary mass spectrometry. LYS4 trimethylation correlates with degree of acetylation on the same $\mathrm{H} 3$ tail. J. Biol. Chem. 282: 27923-27934.

Joshi, A.A. and Struhl, K. 2005. Eaf3 chromodomain interaction with methylated H3-K36 links histone deacetylation to Pol II elongation. Mol. Cell 20: 971-978.

Keogh, M.C., Podolny, V., and Buratowski, S. 2003. Bur1 kinase is required for efficient transcription elongation by RNA polymerase II. Mol. Cell. Biol. 23: 7005-7018.

Keogh, M.C., Kurdistani, S.K., Morris, S.A., Ahn, S.H., Podolny, V., Collins, S.R., Schuldiner, M., Chin, K., Punna, T., Thompson, N.J., et al. 2005. Cotranscriptional set2 methylation of histone $\mathrm{H} 3$ lysine 36 recruits a repressive $\mathrm{Rpd} 3 \mathrm{com}$ plex. Cell 123: 593-605.

Kizer, K.O., Phatnani, H.P., Shibata, Y., Hall, H., Greenleaf, A.L., and Strahl, B.D. 2005. A novel domain in Set2 mediates RNA polymerase II interaction and couples histone H3 K36 methylation with transcript elongation. Mol. Cell. Biol. 25:
$3305-3316$.

Kouzarides, T. 2007. Chromatin modifications and their function. Cell 128: 693-705.

Krogan, N.J., Kim, M., Tong, A., Golshani, A., Cagney, G., Canadien, V., Richards, D.P., Beattie, B.K., Emili, A., Boone, C., et al. 2003. Methylation of histone H3 by Set2 in Saccharomyces cerevisiae is linked to transcriptional elongation by RNA polymerase II. Mol. Cell. Biol. 23: 4207-4218.

Kruger, W., Peterson, C.L., Sil, A., Coburn, C., Arents, G., Moudrianakis, E.N., and Herskowitz, I. 1995. Amino acid substitutions in the structured domains of histones $\mathrm{H} 3$ and $\mathrm{H} 4$ partially relieve the requirement of the yeast SWI/SNF complex for transcription. Genes \& Dev. 9: 2770-2779.

Kuo, M.H. and Allis, C.D. 1999. In vivo cross-linking and immunoprecipitation for studying dynamic Protein:DNA associations in a chromatin environment. Methods 19: 425-433.

Landry, J., Sutton, A., Hesman, T., Min, J., Xu, R.M., Johnston, M., and Sternglanz, R. 2003. Set2-catalyzed methylation of histone H3 represses basal expression of GAL4 in Saccharomyces cerevisiae. Mol. Cell. Biol. 23: 5972-5978.

Latham, J.A. and Dent, S.Y. 2007. Cross-regulation of histone modifications. Nat. Struct. Mol. Biol. 14: 1017-1024.

Li, J., Moazed, D., and Gygi, S.P. 2002. Association of the histone methyltransferase Set2 with RNA polymerase II plays a role in transcription elongation. J. Biol. Chem. 277: 4938349388.

Li, B., Howe, L., Anderson, S., Yates III, J.R., and Workman, J.L. 2003. The Set 2 histone methyltransferase functions through the phosphorylated carboxyl-terminal domain of RNA polymerase II. J. Biol. Chem. 278: 8897-8903.

Li, B., Gogol, M., Carey, M., Lee, D., Seidel, C., and Workman, J.L. 2007a. Combined action of PHD and chromo domains directs the Rpd3S HDAC to transcribed chromatin. Science 316: 1050-1054.

Li, B., Gogol, M., Carey, M., Pattenden, S.G., Seidel, C., and Workman, J.L. 2007b. Infrequently transcribed long genes depend on the Set2/Rpd3S pathway for accurate transcription. Genes \& Dev. 21: 1422-1430.

Luger, K., Mader, A.W., Richmond, R.K., Sargent, D.F., and Richmond, T.J. 1997. Crystal structure of the nucleosome core particle at 2.8 A resolution. Nature 389: 251-260.

Martin, C. and Zhang, Y. 2005. The diverse functions of histone lysine methylation. Nat. Rev. Mol. Cell Biol. 6: 838-849.

Morris, S.A., Rao, B., Garcia, B.A., Hake, S.B., Diaz, R.L., Shabanowitz, J., Hunt, D.F., Allis, C.D., Lieb, J.D., and Strahl, B.D. 2007. Identification of histone $\mathrm{H} 3$ lysine 36 acetylation as a highly conserved histone modification. J. Biol. Chem. 282: 7632-7640.

Murray, S., Udupa, R., Yao, S., Hartzog, G., and Prelich, G. 2001. Phosphorylation of the RNA polymerase II carboxy-terminal domain by the Burl cyclin-dependent kinase. Mol. Cell. Biol. 21: 4089-4096.

Muthurajan, U.M., Bao, Y., Forsberg, L.J., Edayathumangalam, R.S., Dyer, P.N., White, C.L., and Luger, K. 2004. Crystal structures of histone Sin mutant nucleosomes reveal altered protein-DNA interactions. EMBO J. 23: 260-271.

Nelson, C.J., Santos-Rosa, H., and Kouzarides, T. 2006. Proline isomerization of histone $\mathrm{H} 3$ regulates lysine methylation and gene expression. Cell 126: 905-916.

Ng, H.H., Xu, R.M., Zhang, Y., and Struhl, K. 2002. Ubiquitination of histone H2B by Rad6 is required for efficient Dot 1mediated methylation of histone $\mathrm{H} 3$ lysine 79. J. Biol. Chem. 277: 34655-34657.

Pokholok, D.K., Harbison, C.T., Levine, S., Cole, M., Hannett, N.M., Lee, T.I., Bell, G.W., Walker, K., Rolfe, P.A., Herbolsheimer, E., et al. 2005. Genome-wide map of nucleosome 
Du et al.

acetylation and methylation in yeast. Cell 122: 517-527.

Rao, B., Shibata, Y., Strahl, B.D., and Lieb, J.D. 2005. Dimethylation of histone $\mathrm{H} 3$ at lysine 36 demarcates regulatory and nonregulatory chromatin genome-wide. Mol. Cell. Biol. 25: 9447-9459.

Rea, S., Eisenhaber, F., O'Carroll, D., Strahl, B.D., Sun, Z.W., Schmid, M., Opravil, S., Mechtler, K., Ponting, C.P., Allis, C.D., et al. 2000. Regulation of chromatin structure by sitespecific histone H3 methyltransferases. Nature 406: 593599.

Shahbazian, M.D., Zhang, K., and Grunstein, M. 2005. Histone H2B ubiquitylation controls processive methylation but not monomethylation by Dot1 and Set1. Mol. Cell 19: 271-277.

Shi, X., Hong, T., Walter, K.L., Ewalt, M., Michishita, E., Hung, T., Carney, D., Pena, P., Lan, F., Kaadige, M.R., et al. 2006. ING2 PHD domain links histone H3 lysine 4 methylation to active gene repression. Nature 442: 96-99.

Shogren-Knaak, M. and Peterson, C.L. 2006. Switching on chromatin: Mechanistic role of histone H4-K16 acetylation. Cell Cycle 5: 1361-1365.

Strahl, B.D., Grant, P.A., Briggs, S.D., Sun, Z.W., Bone, J.R., Caldwell, J.A., Mollah, S., Cook, R.G., Shabanowitz, J., Hunt, D.F., et al. 2002. Set2 is a nucleosomal histone H3selective methyltransferase that mediates transcriptional repression. Mol. Cell. Biol. 22: 1298-1306.

Suka, N., Luo, K., and Grunstein, M. 2002. Sir2p and Sas2p opposingly regulate acetylation of yeast histone $\mathrm{H} 4$ lysine 16 and spreading of heterochromatin. Nat. Genet. 32: 378-383.

Sun, Z.W. and Allis, C.D. 2002. Ubiquitination of histone H2B regulates $\mathrm{H} 3$ methylation and gene silencing in yeast. $\mathrm{Na}$ ture 418: 104-108.

Taverna, S.D., Li, H., Ruthenburg, A.J., Allis, C.D., and Patel, D.J. 2007. How chromatin-binding modules interpret histone modifications: Lessons from professional pocket pickers. Nat. Struct. Mol. Biol. 14: 1025-1040.

Vaquero, A., Loyola, A., and Reinberg, D. 2003. The constantly changing face of chromatin. Sci. Aging Knowl. Environ. 2003: RE4. doi: 10.1126/sageke.2003.14.re4.

Wechser, M.A., Kladde, M.P., Alfieri, J.A., and Peterson, C.L. 1997. Effects of Sin-versions of histone H4 on yeast chromatin structure and function. EMBO J. 16: 2086-2095.

White, C.L., Suto, R.K., and Luger, K. 2001. Structure of the yeast nucleosome core particle reveals fundamental changes in internucleosome interactions. EMBO J. 20: 5207-5218.

Xiao, T., Hall, H., Kizer, K.O., Shibata, Y., Hall, M.C., Borchers, C.H., and Strahl, B.D. 2003. Phosphorylation of RNA polymerase II CTD regulates H3 methylation in yeast. Genes \& Dev. 17: 654-663. 


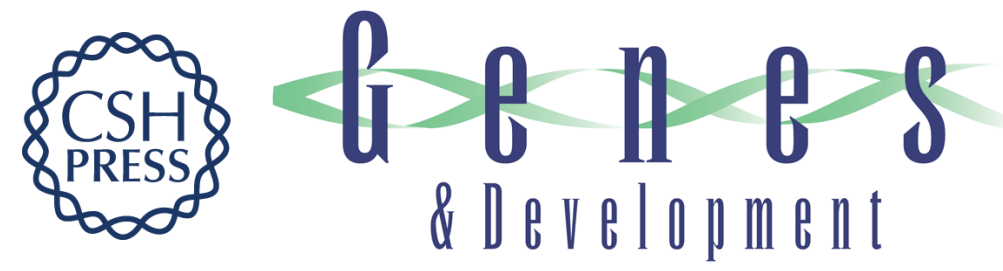

\section{Histone H3 K36 methylation is mediated by a trans-histone methylation pathway involving an interaction between Set2 and histone $\mathrm{H} 4$}

Hai-Ning Du, lan M. Fingerman and Scott D. Briggs

Genes Dev. 2008, 22:

Access the most recent version at doi:10.1101/gad.1700008

Supplemental http://genesdev.cshlp.org/content/suppl/2008/10/17/22.20.2786.DC1

Material

References This article cites 50 articles, 26 of which can be accessed free at:

http://genesdev.cshlp.org/content/22/20/2786.full.html\#ref-list-1

License

Email Alerting Receive free email alerts when new articles cite this article - sign up in the box at the top

Service right corner of the article or click here.

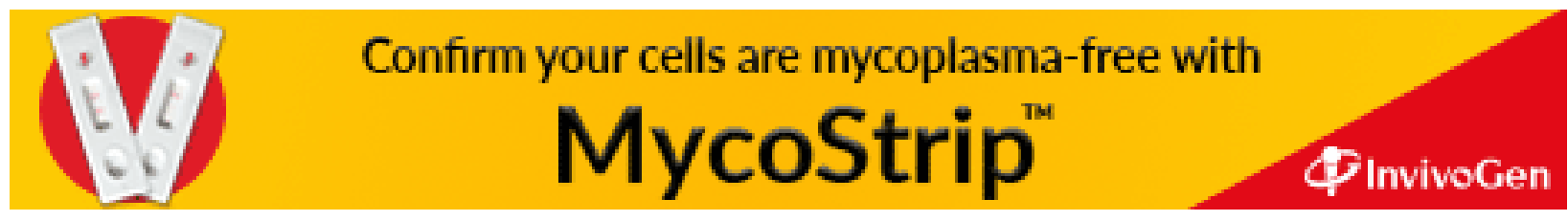

